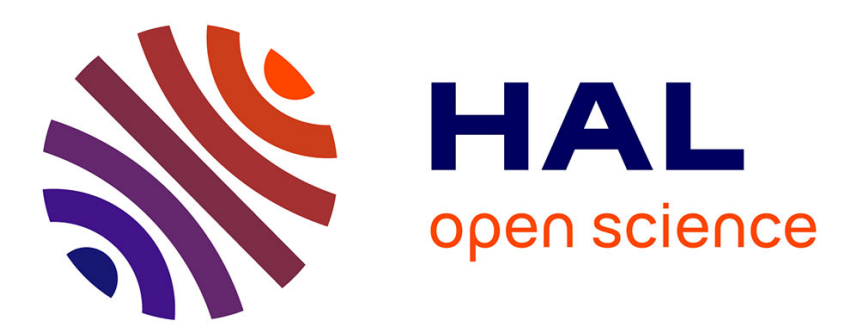

\title{
Unusually large shear wave anisotropy for chlorite in subduction zone settings
}

Mainak Mookherjee, David Mainprice

\section{To cite this version:}

Mainak Mookherjee, David Mainprice. Unusually large shear wave anisotropy for chlorite in subduction zone settings. Geophysical Research Letters, 2014, 41 (5), pp.1506-1513. 10.1002/2014GL059334 . hal-01053707

\section{HAL Id: hal-01053707 https://hal.science/hal-01053707}

Submitted on 3 Nov 2017

HAL is a multi-disciplinary open access archive for the deposit and dissemination of scientific research documents, whether they are published or not. The documents may come from teaching and research institutions in France or abroad, or from public or private research centers.
L'archive ouverte pluridisciplinaire HAL, est destinée au dépôt et à la diffusion de documents scientifiques de niveau recherche, publiés ou non, émanant des établissements d'enseignement et de recherche français ou étrangers, des laboratoires publics ou privés. 


\section{Geophysical Research Letters}

\section{RESEARCH LETTER}

10.1002/2014GL059334

Key Points:

- First report of high pressure elasticity of chlorite

- Unusual shear wave anisotropy for chlorite

- Shear elastic anisotropy explains seismological observations in subduction zones

Supporting Information:

- Text S1

- Figure S1

Correspondence to:

M. Mookherjee,

mainak.mookherjee@cornell.edu

\section{Citation:}

Mookherjee, M., and D. Mainprice (2014), Unusually large shear wave anisotropy for chlorite in subduction zone settings, Geophys. Res. Lett., 41, 1506-1513, doi:10.1002/2014GL059334.

Received 17 JAN 2014 Accepted 6 FEB 2014

Accepted article online 13 FEB 2014 Published online 11 MAR 2014

\section{Unusually large shear wave anisotropy for chlorite in subduction zone settings}

\author{
Mainak Mookherjee ${ }^{1}$ and David Mainprice ${ }^{2}$ \\ ${ }^{1}$ Earth and Atmospheric Sciences, Cornell University, Ithaca, New York, USA, ${ }^{2}$ Geosciences Montpellier UMR CNRS 5243, \\ Université Montpellier 2, Montpellier, France
}

Abstract Using first principle simulations we calculated the elasticity of chlorite. At a density $\rho \sim 2.60 \mathrm{~g} \mathrm{~cm}^{-3}$, the elastic constant tensor reveals significant elastic anisotropy: $V_{P} \sim 27 \%, V_{S 1} \sim 56 \%$, and $V_{S 2} \sim 43 \%$. The shear anisotropy is exceptionally large for chlorite and enhances upon compression. Upon compression, the shear elastic constant component $C_{44}$ and $C_{55}$ decreases, whereas $C_{66}$ shear component stiffens. The softening in $C_{44}$ and $C_{55}$ is reflected in shear modulus, $G$, and the shear wave velocity, $V_{s}$. Our results on elastic anisotropy at conditions relevant to the mantle wedge indicates that a $10-20 \mathrm{~km}$ layer of hydrated peridotite with serpentine and chlorite could account for the observed shear polarization anisotropy and associated large delay times of 1-2 s observed in some subduction zone settings. In addition, chlorite could also explain the low $V_{P} / V_{s}$ ratios that have been observed in recent high-resolution seismological studies.

\section{Introduction}

Chlorite, $\mathrm{Mg}_{5} \mathrm{Al}\left(\mathrm{Si}_{3} \mathrm{Al}\right) \mathrm{O}_{10}(\mathrm{OH})_{8}$, is a layered hydrous silicate mineral with $\sim 13 \mathrm{wt} \%$ water stored in its crystallographic sites. It is an alteration product that is stabilized in the hydrated oceanic lithosphere, metasomatized mantle rocks, and hydrated mantle wedge. Phase equilibria studies indicate that chlorite is stable up to a temperature of $800-820^{\circ} \mathrm{C}$ and pressures of 2.0-3.6 GPa [Pawley, 2003; Fumagalli and Poli, 2005; Grove et al., 2006; Dvir et al., 2011; Till et al., 2012]. Upon subduction, the hydrous phases stable in the hydrated lithosphere become thermodynamically unstable and undergo dehydration [UImer and Trommsdorff, 1995; Schmidt and Poli, 1998; Iwamori, 1998, 2007; Pawley, 2003; Grove et al., 2006]. Dehydration of these hydrous phases, including chlorite has been related with the seismogenic activities along the double Benioff zones [Burdzinski et al., 2007]. In addition fluids are also released by the dehydration of the subducting sediments. The released fluid migrates upward, rehydrates cooler and shallow parts of the slab-wedge interface where hydrous minerals such as serpentine and chlorite are stabilized [Till et al., 2012; Grove et al., 2012]. A fertile peridotite has sufficient $\mathrm{Al}_{2} \mathrm{O}_{3}$ to stabilize 6 to $7 \mathrm{wt} \%$ chlorite in the hydrated lithosphere and in the basal region of the upper mantle wedge [Grove et al., 2012]. Low-velocity layers, observed in seismic images of Honshu subduction zone system [Kawakatsu and Watada, 2007], have been interpreted to indicate the presence of hydrous phases such as chlorite and serpentine in the shallow mantle wedge. Despite the importance of chlorite for our understanding of upper mantle structure and dynamics, little is known of its atomic structure and elasticity at high pressure. What is the effect of pressure on the elastic anisotropy of chlorite? Could elasticity and anisotropy of chlorite explain the (a) observed large delay time ( 1-2 s) between arrival of the two shear waves $V_{S 1}$ and $V_{S 2}$, in certain subduction zones [Long and van der Hilst, 2006; Long and Silver, 2008], (b) the range of $V_{P} / V_{S}$ ratios observed in the mantle wedge [Hacker and Abers, 2012]? To address these fundamental questions, we explore the full elastic constant tensor and anisotropy of chlorite at conditions relevant to mantle wedge.

\section{Method}

Static, density functional theory (DFT) calculations [Hohenberg and Kohn, 1964; Kohn and Sham, 1965] were performed with Vienna ab initio simulation package [Kresse and Hafner, 1993; Kresse and Furthmuller, 1996a, 1996b; Kresse and Joubert, 1999]. The generalized gradient approximation (GGA) [Perdew et al., 1996] and highly accurate projector augmented wave method [Kresse and Joubert, 1999] were used for all calculations. We investigated chlorite, with 72 atoms in a formula unit with $\mathrm{Mg}_{5} \mathrm{Al}\left(\mathrm{Si}_{3} \mathrm{Al}\right) \mathrm{O}_{10}(\mathrm{OH})_{8}$ stoichiometry. We used an energy cutoff $E_{\text {cut }}=600 \mathrm{eV}$, and a Monkhurst-Pack [Monkhurst and Pack, 1976] $2 \times 2 \times 2 k$-point mesh. A series of convergence tests demonstrated that these computational parameters 
Table 1. Equation-of-State Parameters for Chlorite

\begin{tabular}{cccccccccc}
${ }^{\mathrm{a}} \mathrm{E}_{0}(\mathrm{eV})$ & ${ }^{\mathrm{b}} \sigma_{\mathrm{EO}}$ & $V_{0}\left(\AA^{3}\right)$ & $\sigma_{\mathrm{VO}}$ & $\mathrm{K}_{0}(\mathrm{GPa})$ & $\sigma_{\mathrm{KO}}$ & $\mathrm{K}^{\prime}$ & $\sigma_{\mathrm{K}}{ }^{\prime}$ & $P_{\max }(\mathrm{GPa})$ & Method \\
\hline-461.22 & 0.005 & 715.1 & 0.313 & 74.7 & 1.7 & 6.6 & 0.6 & 15.0 & $\mathrm{GGA}^{\mathrm{c}}$ \\
& & 703.5 & 0.160 & 72.3 & 2.4 & 5.4 & 1.0 & 6.5 & $\mathrm{NPD}^{\mathrm{d}}$ \\
& & 703.4 & 0.400 & 71.0 & 0.9 & 8.0 & 0.5 & 5.5 & $\mathrm{SCXRD}^{\mathrm{e}}$ \\
& & 701.3 & 0.190 & 83.4 & 0.7 & & & 3.6 & $\mathrm{SXRPD}^{\mathrm{f}}$ \\
& & 702.6 & 0.400 & 55.0 & 10.0 & & & 4.0 & $\mathrm{SCXRD}^{\mathrm{g}}$ \\
\hline
\end{tabular}

${ }^{a} E_{0}$ refers to the ground state energy from first principles.

${ }^{b} \sigma$ refers to the error associated with the parameters.

'GGA: Generalized Gradient Approximation (this study).

dNPD: neutron powder diffraction [Welch and Marshall, 2001].

eSCXRD: Single-Crystal X-ray diffraction [Zanazzi et al., 2007].

fXXRPD: Synchroton X-ray powder diffraction [Pawley et al., 2002].

ISCXRD: Single-Crystal X-ray diffraction [Hazen and Finger, 1978].

yield total energies that are converged to within $0.2 \mathrm{meV}$. We analyze bulk compression behavior using the third-order Birch Murnaghan equation of state [Birch, 1978]. Full elastic constant tensor was determined by straining the lattice by $1 \%$, the details of the methods are described in Karki et al. [2001]. Finite strain fits to the elasticity data, computation of isotropic bulk $(K)$ and shear $(G)$ moduli were made using the finite strain formulations as in Karki et al. [2001]. Previous studies have shown that DFT captures the relevant physics of hydrous minerals [Mookherjee and Stixrude, 2006, 2009; Mainprice et al., 2007; Tsuchiya and Tsuchiya, 2009; Chantel et al., 2012; Mookherjee and Bezacier, 2012] with varying bond strengths from strong hydroxyl to weak interlayer forces [Mainprice et al., 2008; Mookherjee and Capitani, 2011; Militzer et al., 2011]. We computed the single-crystal azimuthal anisotropy for $P$ and $S$ waves in chlorite using the formulation for maximum polarization anisotropy [Mainprice, 1990].

\section{Results}

Previously reported equation-of-state parameters for chlorite exhibit large variations (Table 1). In particular, the zero pressure value of the bulk modulus ranges from $55.0( \pm 10.0)$ GPa [Hazen and Finger, 1978 ] to $83.4( \pm 0.7) \mathrm{GPa}$ [Pawley et al., 2002]. This is likely to translate to more than $50 \%$ difference in the bulk sound velocity, since the variation in the zero pressure volume between these different sets of experiments is less than $0.3 \%$. The pressure-volume relation and the variation of lattice parameters under compression for chlorite determined using DFT provides tighter constraints on the equation-of-state parameter. The pressure-volume results from DFT for chlorite are well represented by a finite strain formulation, with $K_{0}=74.7( \pm 1.7) \mathrm{GPa}$ and $K_{0}^{\prime}=6.6( \pm 0.6)$. The equation-of-state parameter based on DFT within GGA is in good agreement with recent experimental studies [Welch and Marshall, 2001; Zanazzi et al., 2007] (Figure 1 and Table 1). The static zero pressure volume within GGA is $1.7 \%$ greater and the zero pressure value of the bulk modulus within GGA is $5.2 \%$ greater than the room temperature single-crystal $X$-ray diffraction experimental value [Zanazzi et al., 2007]. We used a Cartesian reference frame for the elastic tensor of $X=a, Y=b$, and $Z=c^{*}$. The linear moduli along $a, b$, and $c^{*}$ axis directions are $K_{a}=258$ $( \pm 6.8), K_{b}=280.2( \pm 4.7)$, and $K_{c}=155.4( \pm 6.4) \mathrm{GPa}$, respectively, in good agreement with a recent singlecrystal X-ray diffraction study [Zanazzi et al., 2007] (Table 2). The calculated elastic constants show substantially softer elasticity along the stacking direction $\left(c^{*}\right)$ (Table 3 and Figure 2 ). The elastic constants also exhibit striking anisotropy at ambient pressures. At ambient pressures, $C_{11} \sim C_{22}$ is 1.4 times greater than $C_{33}$, reflecting weaker bonding along [001] direction. The principle elastic moduli, $C_{33}$, increases

Table 2. Lattice Parameters and Linear Moduli for Chlorite

\begin{tabular}{ccccccccccccc}
$a_{0}(\AA)$ & $\sigma_{\mathrm{a} 0}{ }^{\mathrm{a}}$ & $\mathrm{K}_{\mathrm{a}}(\mathrm{GPa})$ & $\sigma_{\mathrm{Ka}}$ & $\sigma_{0}(\AA)$ & $\sigma_{\mathrm{b} 0}$ & $\mathrm{~K}_{\mathrm{b}}(\mathrm{GPa})$ & $\sigma_{\mathrm{Kb}}$ & $c_{0}(\AA)$ & $\sigma_{\mathrm{c} 0}$ & $\mathrm{~K}_{\mathrm{c}}(\mathrm{GPa})$ & $\sigma_{\mathrm{Kc}}$ & Method \\
\hline 5.3624 & 0.0001 & 258.00 & 6.8 & 9.292 & 0.001 & 280.2 & 4.7 & 14.367 & 0.01 & 155.4 & 67.4 & $\mathrm{GGA}^{\mathrm{b}}$ \\
5.3363 & 0.0009 & 263.15 & 0.3 & 9.240 & 0.001 & 277.8 & 0.3 & 14.265 & 0.03 & 185.2 & 0.9 & $\mathrm{SCXRD}^{\mathrm{c}}$ \\
\hline
\end{tabular}

${ }_{0}^{a} \sigma$ refers to the error associated with the parameters.

${ }^{b}$ GGA: Generalized Gradient Approximation (this study).

CSCXRD: Single-Crystal X-ray diffraction [Zanazzi et al., 2007]. 


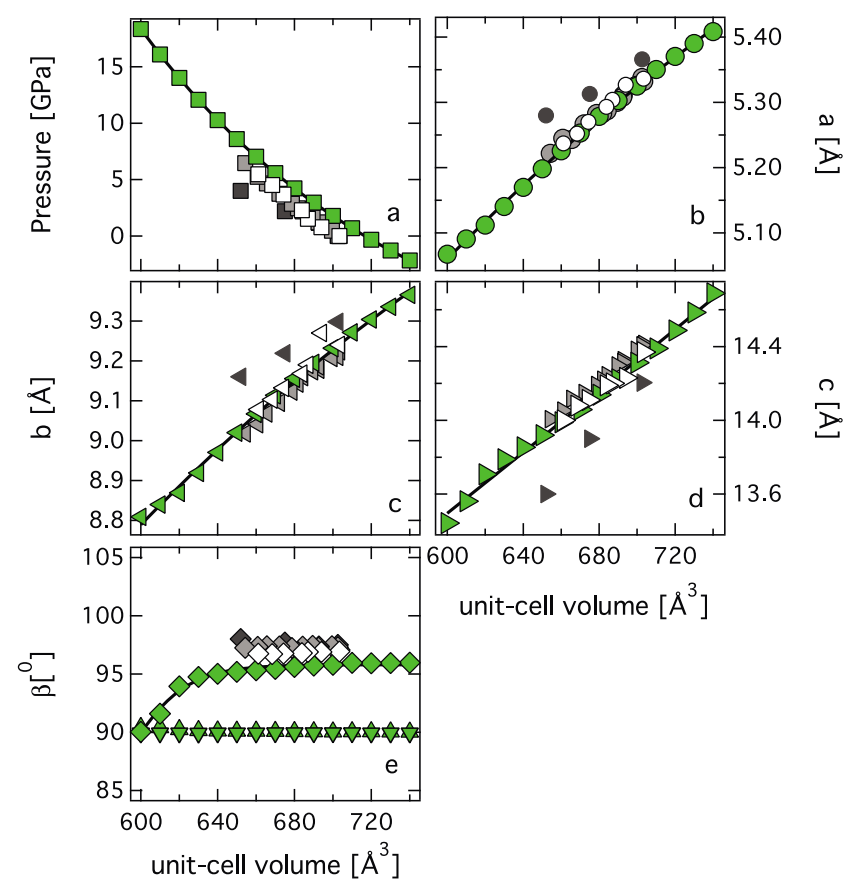

Figure 1. Plot of (a) pressure, (b) $a$ axis, (c) $b$ axis, (d) $c$ axis, and (e) lattice parameter $\beta$ versus unit-cell volume. Result from the simulations (GGA) (this study) is denoted with "light green filled symbols" and compared with previous X-ray diffraction results denoted by "dark grey" [Hazen and Finger, 1978], "light grey symbols" [Welch and Marshall, 2001], and "white" symbols [Zanazzi et al., 2003]. The black lines denote finite strain fits.

rapidly upon compression, with $\partial C_{33} / \partial P \sim 14$ (Table 3). This is similar to other layered hydrous phases including serpentine and talc [Mookherjee and Stixrude, 2009; Mookherjee and Capitani, 2011; Bezacier et al., 2013]. The strong anisotropy is also reflected in shear elastic constants via the ratio $C_{66} / C_{44}$, where $C_{66}$ governs shear deformation of the T-O sheets, and $C_{44}$ shear sliding of sheets across each other. The $C_{66} / C_{44}$ ratio increases from 2.8 at ambient conditions to 4.2 at $7 \mathrm{GPa}$. The principal elastic constants of chlorite increase monotonically with pressure until 10 GPa. Above 10 GPa, the pressure dependence of the elastic constants exhibits anomalous behavior (Figure 2). Previous experimental studies have given some indications of anomalous compressional behavior in chlorite related to the behavior of protons upon compression [Kleppe et al., 2003; Welch et al., 2004]. In agreement with the experiments, we do observe reorientation of the protons upon compression (Figure S1 in the supporting information). Orientation-averaged isotropic bulk and shear moduli, and the compressional and shear wave velocities are in good agreement with our computed equation of state, and with experimental measurements (Figure 2).

Table 3. Pressure Dependence of the Full Elastic Constant Tensor $\left(C_{i j}\right)$, Bulk (K), and Shear $(G)$ Modulus for Chlorite Using First Principles Simulations ${ }^{a}$

\begin{tabular}{|c|c|c|c|c|c|c|c|c|c|c|c|c|c|c|c|c|c|}
\hline V & $\rho$ & $P$ & $C_{11}$ & $C_{22}$ & $C_{33}$ & $C_{44}$ & $C_{55}$ & $C_{66}$ & $C_{12}$ & $C_{13}$ & $C_{23}$ & $C_{15}$ & $C_{25}$ & $C_{35}$ & $C_{46}$ & $K$ & $G$ \\
\hline$\left(\AA^{3}\right)$ & $\left(\mathrm{g} / \mathrm{cm}^{3}\right)$ & \multicolumn{16}{|c|}{ (GPa) } \\
\hline 720 & 2.53 & -0.3 & 197.8 & 202.3 & 135.1 & 24.5 & 24.4 & 70.3 & 60.7 & 21.1 & 34.1 & 3.3 & 0.2 & 0.4 & 0.1 & 82.6 & 45.7 \\
\hline 700 & 2.60 & 1.8 & 202.0 & 199.7 & 152.7 & 23.9 & 23.9 & 72.0 & 58.0 & 22.4 & 27.3 & 3.4 & -0.3 & 0.7 & 0.5 & 83.9 & 46.8 \\
\hline 680 & 2.67 & 4.2 & 199.4 & 204.7 & 198.2 & 23.0 & 20.9 & 73.8 & 56.6 & 34.5 & 40.3 & 3.9 & 0.0 & 1.4 & 0.1 & 95.9 & 46.5 \\
\hline 660 & 2.75 & 7.0 & 209.8 & 207.1 & 233.4 & 17.9 & 16.5 & 74.8 & 60.3 & 45.2 & 49.5 & 4.4 & -0.5 & 2.7 & -0.2 & 106.5 & 43.5 \\
\hline 640 & 2.84 & 10.3 & 220.5 & 216.1 & 284.5 & 11.8 & 11.8 & 76.6 & 66.7 & 66.2 & 70.0 & 6.1 & 1.2 & 5.0 & 0.2 & 123.6 & 39.3 \\
\hline 620 & 2.93 & 14.0 & 236.2 & 229.8 & 316.3 & 6.7 & 11.6 & 77.7 & 77.1 & 77.0 & 78.8 & 10.5 & 4.1 & 10.0 & 2.0 & 134.6 & 36.9 \\
\hline 600 & 3.03 & 18.4 & 251.0 & 240.6 & 299.8 & 21.8 & 32.4 & 79.6 & 84.5 & 77.3 & 73.1 & 20.0 & 4.6 & 22.0 & 3.8 & 136.2 & 53.7 \\
\hline \multicolumn{18}{|c|}{ Finite Strain Fit } \\
\hline 715 & 2.54 & 0 & $\begin{array}{c}198.4 \\
(2.0)\end{array}$ & $\begin{array}{c}197.7 \\
(1.6)\end{array}$ & $\begin{array}{l}138.1 \\
(14.2)\end{array}$ & $\begin{array}{c}25.9 \\
(-1.2)\end{array}$ & $\begin{array}{c}24.6 \\
(-1.2)\end{array}$ & $\begin{array}{l}71.0 \\
(0.5)\end{array}$ & $\begin{array}{l}57.3 \\
(0.4)\end{array}$ & $\begin{array}{l}14.0 \\
(4.7)\end{array}$ & $\begin{array}{l}19.6 \\
(4.9)\end{array}$ & $\begin{array}{c}3.0 \\
(0.2)\end{array}$ & $\begin{array}{l}-0.5 \\
(0.1)\end{array}$ & $\begin{array}{c}0.1 \\
(0.4)\end{array}$ & $\begin{array}{c}0.1 \\
(0.01)\end{array}$ & $\begin{array}{l}79.2 \\
(3.7)\end{array}$ & $\begin{array}{c}47.4 \\
(-0.3)\end{array}$ \\
\hline
\end{tabular}

${ }^{\mathrm{a}}$ In addition, the finite strain fit results are also tabulated. The values in the bracket () denote the pressure derivatives $d C_{i j} / d P$. 


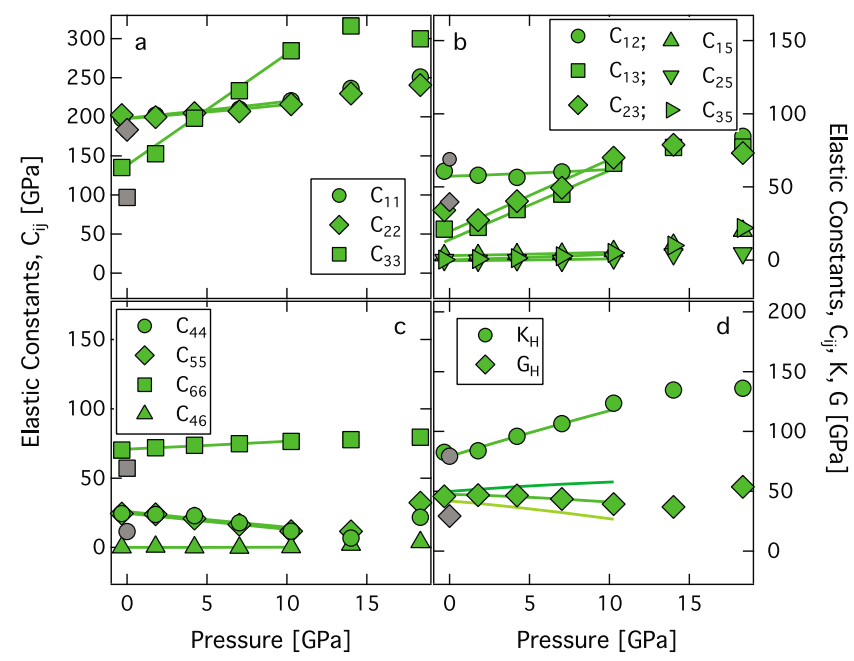

Figure 2. Elastic constants $\left(C_{i j}\right)$ as a function of pressure, (a) compressional components, $C_{11}, C_{22}$, and $C_{33}$; (b) off-diagonal components, $\mathrm{C}_{12}, \mathrm{C}_{13}, \mathrm{C}_{23}, \mathrm{C}_{15}, \mathrm{C}_{25}$, and $\mathrm{C}_{35}$; (c) shear components, $\mathrm{C}_{44}, \mathrm{C}_{55}, \mathrm{C}_{66}$, and $\mathrm{C}_{46}$; and (d) plot of bulk ( $\mathrm{K}$ ) and shear $(G)$ modulus versus pressure. The "green" symbols refer to the predictions from simulation (this study), the grey symbols refer to the room pressure data [Alexandrov and Ryzhova, 1961]. In Figure 2d, subscript " $\mathrm{H}$ " refers to the Hill average. Finite strain fits for Voigt, Hill, and Ruess limits are plotted. For the bulk (K) modulus, the Voigt and Ruess bounds are tighter, for the shear (G) modulus, the bounds are divergent with Voigt bounds shown in "dark green" line and the Reuss bounds are shown in "light green" line. The lines refer to the finite strain fit up to $10 \mathrm{GPa}$ beyond which the pressure dependence of elasticity exhibits anomalous behavior.
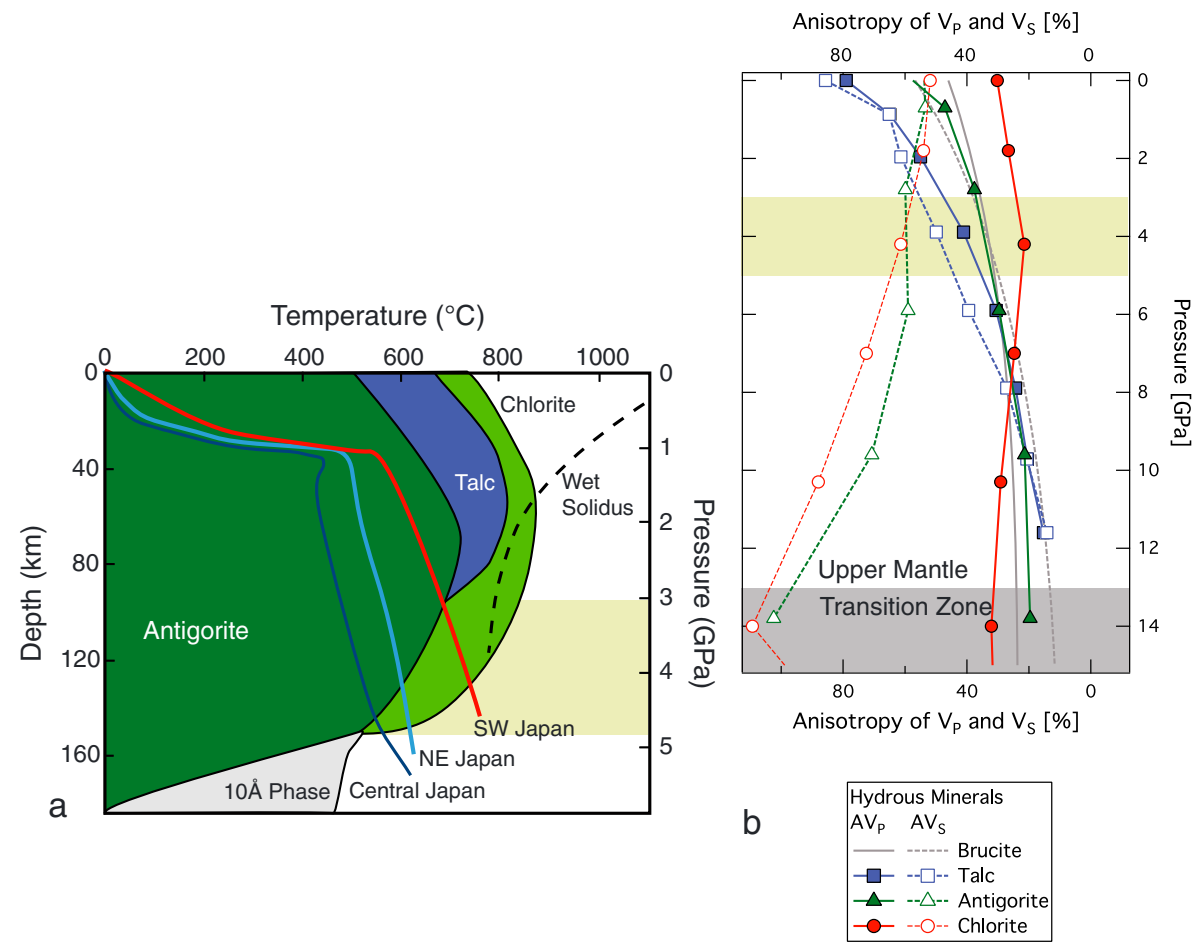

Figure 3. (a) Thermodynamic stability of hydrous phases including, antigorite [Ulmer and Trommsdorff, 1995], chlorite [Grove et al., 2006], talc [Pawley and Wood, 1995], and $10 \AA$ A phase [Fumagalli and Poli, 2005]. Also shown are the subduction geotherms [/wamori, 2007], the "light green" band indicates the depth range of stability of chlorite and (b) plot of seismic anisotropy of various hydrous phases including, brucite [Jiang et al., 2006], antigorite [Mookherjee and Capitani, 2011], talc [Mainprice et al., 2008], and chlorite (this study). We note that the $S$ wave anisotropy for antigorite and chlorite increases dramatically under compression. The depth range of stability for chlorite is indicated with the light green band. 
a
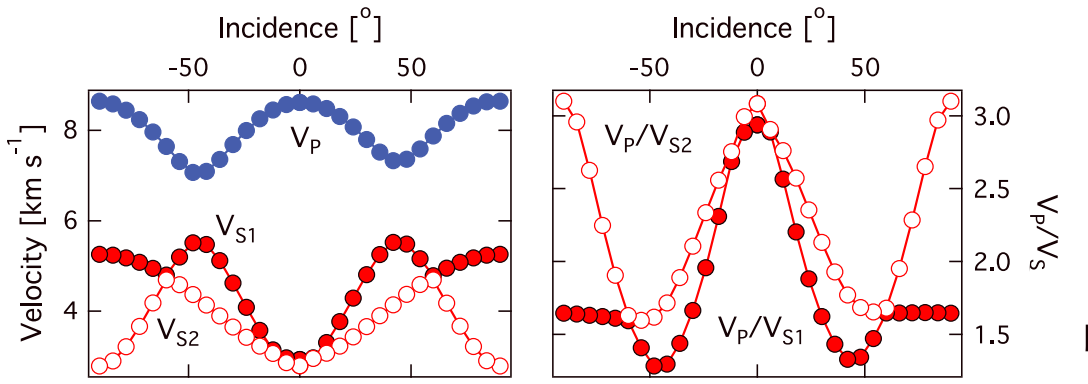

$\mathrm{b}$
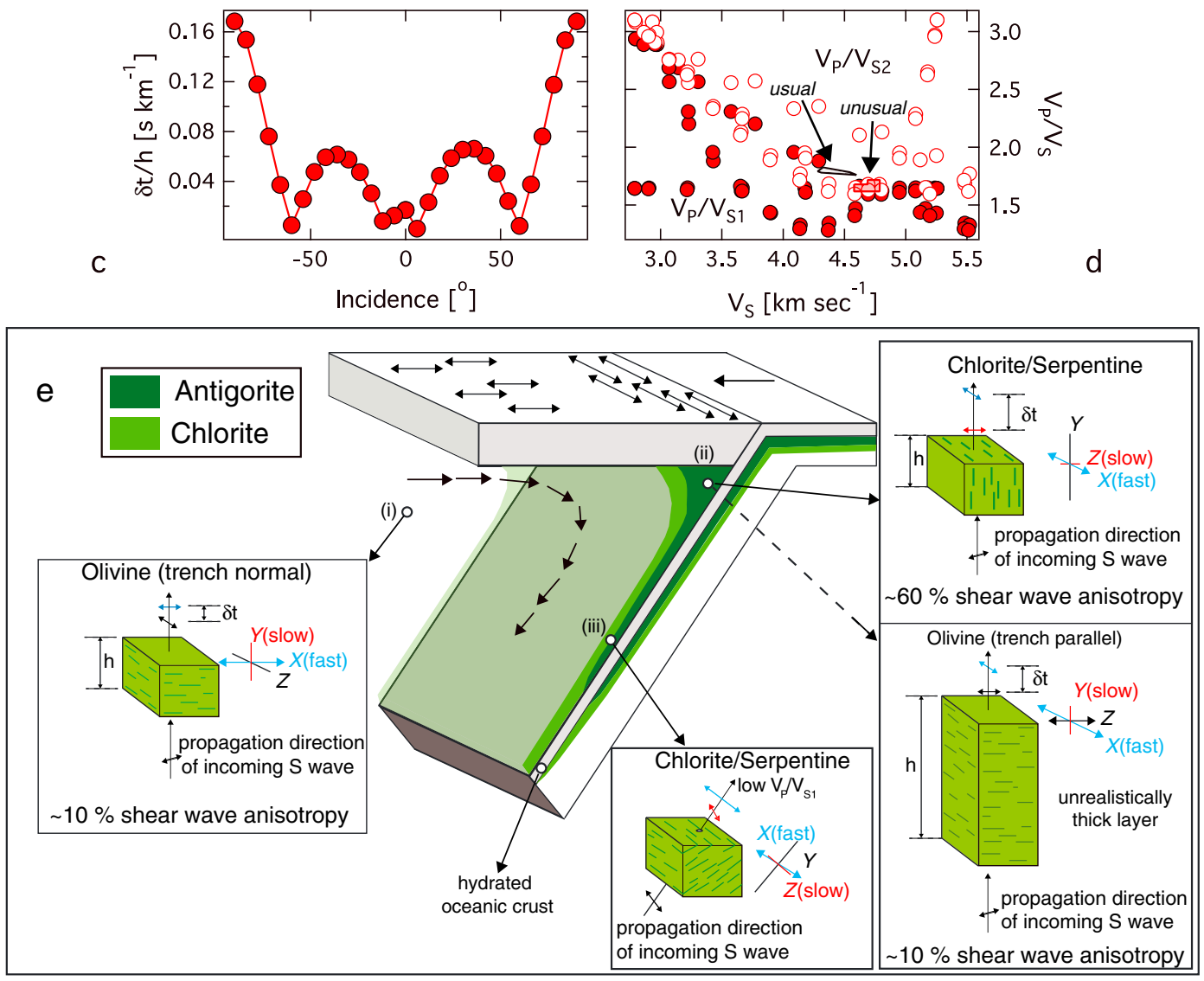

Figure 4. Anisotropy of chlorite variation of (a) $V_{P} V_{S 1}$, and $V_{S 2} ;$ (b) $V_{P} / V_{S 1}$ and $V_{P} / V_{S 2} ;$ (c) delay time/layer thickness, $\delta V_{S} /\left(V_{S 1} \times V_{S 2}\right)$, as a function of the angle of incidence with respect to [001] plane of chlorite at condition relevant to subduction zone (density $\sim 2.67 \mathrm{~g} / \mathrm{cm}^{3}$ ), $0^{\circ}$ refers to the seismic ray parallel to the [001] direction and $90^{\circ}$ refers to the seismic rays oriented perpendicular to the [001] direction; and (d) plot of $V_{P} / V_{S}$ versus $V_{S}$. Two regions marked with black and red lines refer to the "usual" $\left(4.28<V_{S}<4.59 \mathrm{~km} \mathrm{~s}^{-1}\right.$ and $\left.1.76<V_{P} / V_{S}<1.82\right)$ and "unusual" $\left(4.58<V_{S}<4.79 \mathrm{~km} \mathrm{~s}^{-1}\right.$ and $1.62<V_{P} / V_{S}<1.72$ ] [Hacker and Abers, 2012] velocity ratios observed from the mantle wedges in subduction zone settings. The "unusual" observed velocities are observed in the depth range of 50-100 km depth in a typical subduction zone settings [Hacker and Abers, 2012]. Note: filled and open symbols refer to $V_{S 1}$ and $V_{S 2}$, respectively, (e) a schematic diagram of subduction zone indicating the stability fields of antigorite and chlorite, following recent work [Till et al., 2012]. Also shown are the schematic representations of the CPO and the incident rays in different regions (i) mantle overlying the subducting slab, region where the fabric is dominated by olivine and produces trench normal shear wave polarization (ii) hydrated mantle wedge is likely to be dominated by antigorite and chlorite and the near vertical teleseismic rays are likely to generate large delay time, and low $V_{P} / V_{S 1}$ velocity ratios. If this region were to be dominated by olivine, an unrealistically thick layer would have been required to produce large delay time owing to lower shear wave anisotropy of olivine [Kumazawa and Anderson, 1969] (iii) above the subducting slabs, the (001) planes are likely to be aligned parallel to the foliation and seismic rays from the local earthquakes are likely to traverse these hydrated assemblages of rock to produce low $V_{P} / V_{S 1}$. 


\section{Discussion}

The subduction of hydrated lithosphere leads to dehydration and subsequent rehydration of the parts of the overlying mantle wedge. Mantle wedges are often characterized by various geophysical observations including anomalous shear wave velocity [Bostock et al., 2002; Kawakatsu and Watada, 2007], large delay times and trench parallel anisotropy [Long and Silver, 2008], and large $P$ to $S$ wave velocity ratios [Hacker and Abers, 2012, and references therein]. All these observations have been attributed to presence of hydrous phases [Faccenda et al., 2008; Katayama et al., 2009; Mainprice and Ildefonse, 2009; Kim et al., 2012, 2013; Jung, 2011; Reynard, 2012; Wagner et al., 2013; Faccenda, 2014]. In a hydrated fertile peridotite, chlorite is likely to be stable in addition to serpentine. Thermodynamic stability of chlorite is likely to exceed beyond the stability limits of antigorite along warmer slab geotherms [Fumagalli and Poli, 2005; Grove et al., 2006; Till et al., 2012]. Based on the subduction zone geotherms of Iwamori [2007] for central, NE, and SW Japan, it is estimated that a stable chlorite layer thickness between 5, 20, and $40 \mathrm{~km}$, respectively, at depths between 100 and $150 \mathrm{~km}$, corresponding to $3-5 \mathrm{GPa}$ and $550-750^{\circ} \mathrm{C}$.

Based on our study, the most striking feature of the elasticity of chlorite is the pressure dependence of $P$ and $S$ wave anisotropy (Figure 3). In a warm subduction zone geotherm such as Cascadia or southwest Japan, chlorite is likely to be stable between a depth range of $100-130 \mathrm{~km}$, whereas antigorite followed by chlorite is likely to be stable between 120 and $150 \mathrm{~km}$ in a relatively cold subduction zone such as northeast Japan (Figure 3). For other layered hydrous minerals relevant for subduction zone settings, such as brucite and talc, both $P$ and $S$ wave anisotropy decrease with increasing pressure [Mainprice and Ildefonse, 2009]. In contrast, the $S$ wave anisotropy of antigorite and chlorite increases in the depth range 100-150 km (3-5 GPa), so that the anisotropy of antigorite and chlorite are $\sim 60 \%$ higher than that of brucite ( 35\%) and talc (50\%), whereas $P$ wave anisotropy of chlorite $(\sim 20 \%)$ is lower than brucite $(\sim 35 \%)$, antigorite $(\sim 40 \%)$, and talc $(\sim 40 \%)$. As the slab reaches greater depth, dense hydrous phases, such as phase $D$, are likely candidates for transporting the water into the deeper parts of the mantle. A sharp contrast in shear wave anisotropy is to be expected as the subducting slabs reach greater depths since the dense hydrous phases such as phase $D$ have significantly lower shear wave anisotropy (18-19\%) [Mainprice et al., 2007; Rosa et al., 2012].

The full elastic stiffness tensor, elastic anisotropy, and its pressure dependence suggests that a conservative estimate of 10-20 km layer thickness of hydrated peridotite with chlorite and serpentine could account for a large delay time of around 1.4-2.8 s, assuming perfect crystal alignment (Figure 4). Chlorite is stable to higher temperatures and pressures than antigorite; therefore, a wider range of depth will be characterized by an $S$ wave anisotropy similar to antigorite. Intergrowths of antigorite and chlorite [Morales et al., 2013] result in the crystal preferred orientation (CPO) of antigorite and chlorite being similar to other layered silicates with pole of (001) plane oriented normal to the foliation [Morales et al., 2013; Padron-Navarta et al., 2012; Puelles et al., 2012]. The combined stability range of antigorite and chlorite increases the potential anisotropic zone thickness to 2 to 3 times the chlorite stability field. In addition, elastic anisotropy of chlorite could explain a wide range of $V_{P} / V_{S 1}$ and $V_{P} / V_{S 2}$ ratios. For instance, the rays traversing parallel to the (001) basal planes of chlorite, the $V_{P} / V_{S 1}$ ratio could be as low as 1.30-1.60, whereas rays traversing perpendicular to the (001) basal planes has $V_{P} / V_{S 1} \sim 3.14$ (Figure 3). Such low $V_{P} / V_{S}$ could account for recent high-resolution seismological observations [Wagner et al., 2005, 2006; Rossi et al., 2006; Eberhart-Phillips et al., 2006; Hacker and Abers, 2012].

Acknowledgments

M.M. is supported by the U.S. National Science Foundation grant (EAR-1250477). M.M. acknowledges computing resources (request EAR130015) from the Extreme Science and Engineering Discovery Environment (XSEDE), which is supported by National Science Foundation grant OCl-1053575. Authors acknowledge constructive comments from an anonymous reviewer and YoungHee Kim.

The Editor thanks Manuele Faccenda and YoungHee Kim for their assistance in evaluating this paper.

\section{References}

Alexandrov, K. S., and T. V. Ryzhova (1961), Elastic properties of rock-forming minerals. II. Layered silicates, Bull. Acad. Sci. U.S.S.R., Geophys. Ser., 9, 1165-1168.

Bezacier, L., B. Reynard, H. Cardon, G. Montagnac, and J. D. Bass (2013), High-pressure elasticity of serpentine and seismic properties of the hydrated mantle wedge, J. Geophys. Res. Solid Earth, 118, 527-535, doi:10.1002/jgrb.50076.

Birch, F. (1978), Finite strain isotherm and velocities for single-crystal and polycrystalline NaCl at high-pressures and 300 K, J. Geophys. Res., 83, $1257-1268$. Bostock, M. G., R. D. Hyndman, S. Rondenay, and S. M. Peacock (2002), An inverted continental Moho and serpentinization of the forearc mantle, Nature, 417, 536-538.

Burdzinski, M. R., C. H. Thurber, B. R. Hacker, and E. R. Engdahl (2007), Global prevalence of double Benioff zones, Science, 316, $1472-1474$. Chantel, J., M. Mookherjee, and D. J. Frost (2012), The elasticity of lawsonite at high pressure and the origin of the low velocity layers in subduction zones, Earth Planet. Sci. Lett., 349-350, 116-125.

Dvir, O., T. Pettke, P. Fumagalli, and R. Kessel (2011), Fluids in the peridotite-water system up to $6 \mathrm{GPa}$ and $800^{\circ} \mathrm{C}$ : New experimental constrains on dehydration reactions, Contrib. Mineral. Petrol., 161, 829-844.

Eberhart-Phillips, D., D. H. Christensen, T. M. Brocher, R. Hansen, N. A. Rupert, P. J. Haeussler, and G. A. Abers (2006), Imaging the transition from Aleutian subduction to Yakutat collision in central Alaska, with local earthquakes and active source data, J. Geophys. Res., 111, B11303, doi:10.1029/2005JB004240. 
Faccenda, M. (2014), Water in the slab: A trilogy, Tectonophysics, 614, 1-30, doi:10.1016/j.tecto.2013.12.020.

Faccenda, M., L. Burlini, T. V. Gerya, and D. Mainprice (2008), Fault-induced seismic anisotropy by hydration in subducting oceanic plates, Nature, 455, 1097-1101.

Fumagalli, P., and S. Poli (2005), Experimentally determined phase relations in hydrous peridotites to $6.5 \mathrm{GPa}$ and their consequences on the dynamics of subduction zones, J. Petrol., 46, 555-578.

Grove, T. L., N. Chatterjee, S. W. Parman, and E. Medard (2006), The influence of $\mathrm{H}_{2} \mathrm{O}$ on mantle wedge melting, Earth Planet. Sci. Lett., 249, 74-89. Grove, T. L., C. B. Till, and M. Krawczynski (2012), The role of $\mathrm{H}_{2} \mathrm{O}$ in subduction zone magmatism, Annu. Rev. Earth Planet. Sci., 40, 413-439. Hacker, B. R., and G. A. Abers (2012), Subduction Factory 5: Unusually low Poisson's ratios in subduction zones from elastic anisotropy of peridotite, J. Geophys. Res., 117, B06308, doi:10.1029/2012JB009187.

Hazen, R. M., and L. W. Finger (1978), The crystal structures and compressibilities of layer minerals at high pressure. II. Phlogopite and chlorite, Am. Mineral., 63, 293-296.

Hohenberg, P., and W. Kohn (1964), Inhomogenous electron gas, Phys. Rev. B, 136, B864-B871.

Iwamori, H. (1998), Transportation of $\mathrm{H}_{2} \mathrm{O}$ and melting in subduction zones, Earth Planet. Sci. Lett., 160, 65-80.

Iwamori, H. (2007), Transportation of $\mathrm{H}_{2} \mathrm{O}$ beneath the Japan arcs and its implications for global water circulation, Chem. Geol., 239, 182-198.

Jiang, F., S. Speziale, and T. S. Duffy (2006), Single-crystal elasticity of brucite, $\mathrm{Mg}(\mathrm{OH})_{2}$ to $15 \mathrm{GPa}$ by Brillouin scattering, Am. Mineral., 91, 1893-1900.

Jung, H. (2011), Seismic anisotropy produced by serpentine in mantle wedge, Earth Planet. Sci. Lett., 307, 535-543.

Karki, B. B., L. Stixrude, and R. M. Wentzcovitch (2001), High-pressure elastic properties of major materials of Earth's mantle from first principles, Rev. Geophys., 39, 507-534.

Katayama, I., K.-I. Hirauchi, K. Michibayashi, and J.-I. Ando (2009), Trench-parallel anisotropy produced by serpentine deformation in hydrated mantle wedge, Nature, 461, 1114-1117.

Kawakatsu, H., and S. Watada (2007), Seismic evidence for deep-water transportation in the mantle, Science, 316, 1468-1471.

Kim, Y., R. W. Clayton, and J. M. Jackson (2012), Distribution of hydrous minerals in the subduction system beneath Mexico, Earth Planet. Sci. Lett., 341-344, 58-67.

Kim, Y., R. W. Clayton, P. D. Asimow, and J. M. Jackson (2013), Generation of talc in the mantle wedge and its role in subduction dynamics in central Mexico, Earth Planet. Sci. Lett., 384, 81-87.

Kleppe, A. K., A. P. Jephcoat, and M. D. Welch (2003), The effect of pressure on hydrogen bonding in chlorite: A high-pressure Raman spectroscopic study of clinochore to $26.5 \mathrm{GPa}$, Am. Mineral., 88, 567-573.

Kohn, W., and L. J. Sham (1965), Self-consistent equations including exchange and correlation effects, Phys. Rev., 140, $1133-1138$.

Kresse, G., and J. Furthmuller (1996a), Efficiency of ab-initio total energy calculations for metals and semiconductors using a plane-wave basis set, Comput. Mater. Sci., 6, 15-50.

Kresse, G., and J. Furthmuller (1996b), Efficient iterative schemes for ab initio total-energy calculations using a plane-wave basis set, Phys. Rev. $B, 54,11,169-11,186$.

Kresse, G., and J. Hafner (1993), Ab initio molecular-dynamics for liquid-metals, Phys. Rev. B, 47, 558-561.

Kresse, G., and D. Joubert (1999), From ultrasoft pseudopotentials to the projector augmented-wave method, Phys. Rev. B, 59, $1758-1775$

Kumazawa, M., and O. L. Anderson (1969), Elastic moduli, pressure derivatives, and temperature derivatives of single-crystal olivine and single-crystal forsterite, J. Geophys. Res., 74, 5961-5972.

Long, M. D., and P. G. Silver (2008), The subduction zone flow field from seismic anisotropy: A global view, Science, 319, 315-318.

Long, M. D., and R. D. van der Hilst (2006), Shear wave splitting from local events beneath the Ryukyu arc: Trench parallel anisotropy in the mantle wedge, Phys. Earth Planet. Inter., 155, 300-312.

Mainprice, D. (1990), A fortran program to calculate seismic anisotropy from the lattice preferred orientation of minerals, Comput. Geosci., 16, 385-393.

Mainprice, D., and B. Ildefonse (2009), Seismic anisotropy of subduction zone minerals-contribution of hydrous phases, in Subduction Zone Geodynamics, Frontiers in Earth Sciences, edited by S. Lallemand and F. Funiciello, pp. 63-84, Springer-Verlag, Berlin, Heidelberg

Mainprice, D., Y. Le Page, J. Rodgers, and P. Jouanna (2007), Predicted elastic properties of the hydrous D phase at mantle pressures: Implications for the anisotropy of subducted slabs near $670 \mathrm{~km}$ discontinuity and in the lower mantle, Earth Planet. Sci. Lett., 259, 283-296, doi:10.1016/j.epsl.2007.04.053.

Mainprice, D., Y. Le Page, J. Rodgers, and P. Jouanna (2008), Ab initio elastic properties of talc from 0 to 12 GPa: Interpretation of seismic velocities at mantle pressures and prediction of auxetic behavior at low pressure, Earth Planet. Sci. Lett., 274, $327-338$.

Militzer, B., H.-R. Wenk, S. Stackhouse, and L. Stixrude (2011), First-principles calculation of the elastic moduli of sheet silicates and their application to shale anisotropy, Am. Mineral., 96, 125-137.

Mookherjee, M., and L. Bezacier (2012), The low-velocity layer in subduction zone: Structure and elasticity of glaucophane at high pressures, Phys. Earth Planet. Inter., 208-209, 50-58.

Mookherjee, M., and G. C. Capitani (2011), Trench parallel anisotropy and large delay times: Elasticity and anisotropy of antigorite at high pressures, Geophys. Res. Lett., 38, L09315, doi:10.1029/2011GL047160.

Mookherjee, M., and L. Stixrude (2006), High-pressure proton disorder in brucite, Am. Mineral., 91, 127-134.

Mookherjee, M., and L. Stixrude (2009), Structure and elasticity of serpentine at high-pressure, Earth Planet. Sci. Lett., $279,11-19$.

Monkhorst, H. J., and J. D. Pack (1976), Special points for Brillouin-zone integrations, Phys. Rev.B, 13, 5188-5192.

Morales, L. F. G., D. Mainprice, and F. Boudier (2013), The influence of hydrous phase on the microstructure and seismic properties of a hydrated mantle rock, Tectonophysics, 594, 103-117.

Padron-Navarta, J. A., A. Tommasi, C. J. Garrido, and V. Sanchez-Vizcaino (2012), Plastic deformation and development of antigorite crystal preferred orientations in high-pressure serpentinites, Earth Planet. Sci. Lett., 349-350, 75-86.

Pawley, A. (2003), Chlorite stability in mantle peridotite: the reaction clinochlore + enstatite $=$ forsterite + pyrope $+\mathrm{H}_{2} \mathrm{O}, \mathrm{Contrib}$. Mineral. Petrol., 144, 449-456.

Pawley, A. R., and B. J. Wood (1995), The high-pressure stability of talc and $10 \AA$ phase: Potential storage sites for $\mathrm{H}_{2} \mathrm{O}$ in subduction zones, Am. Mineral., 80, 998-1003.

Pawley, A. R., S. M. Clark, and N. J. Chinnery (2002), Equation of state measurements of chlorite, pyrophyllite, and talc, Am. Mineral., 87, 1172-1182. Perdew, J. P., K. Burke, and M. Erzerhof (1996), Generalized gradient approximation made simple, Phys. Rev. Lett., 77, $3865-3868$.

Puelles, P., J. I. Gil Ibarguchi, A. Beranoaguirre, and B. Abalos (2012), Mantle wedge deformation recorded by high-temperature peridotite fabric superposition and hydrous retrogression (Limo massif, Cabo Ortegal, NW Spain), Int. J. Earth Sci, 101, 1835-1853.

Reynard, B. (2012), Serpentine in active subduction zones, Lithos, 178, 171-185. 
Rosa, A. D., C. Sanchez-Valle, and S. Ghosh (2012), Elasticity of phase D and its implication for the degree of hydration of deep subducted slabs, Geophys. Res. Lett., 39, L06304, doi:10.1029/2012GL050927.

Rossi, G., G. Abers, S. Rondenay, and D. H. Chiristensen, (2006), Unusual mantle Poission's ratio, subduction, and crustal structure in central Alaska, J. Geophys. Res., 111, B09311, doi:10.1029/2005JB003956.

Schmidt, M. W., and S. Poli (1998), Experimentally based water budgets for dehydrating slabs and consequences for arc magma generation Earth Planet. Sci. Lett., 163, 361-379.

Till, C. B., T. L. Grove, and A. C. Withers (2012), The beginnings of hydrous mantle wedge melting, Contrib. Mineral. Petrol., 163, 669-688.

Tsuchiya, J., and T. Tsuchiya (2009), Elastic properties of $\delta$-AlOOH under pressure-first principle investigation, Phys. Earth Planet. Inter., 174 $122-127$.

Ulmer, P., and V. Trommsdorff (1995), Serpentine stability to mantle depths and subduction related magmatism, Science, 268, 858-861.

Wagner, L. S., S. L. Beck, and G. Zandt (2005), Upper mantle structure in the south central Chilean subduction zone (30 to $36 \mathrm{~S})$, J. Geophys. Res., 110, B01308, doi:10.1029/2004JB003238.

Wagner, L. S., S. L. Beck, G. Zandt, and M. Ducea (2006), Depleted lithosphere, cold, trapped asthenosphere, and frozen melt puddles above the flat slab in central Chile and Argentina, Earth Planet. Sci. Lett., 245, 289-301.

Wagner, L. S., M. J. Fouch, D. E. James, and M. D. Long (2013), The role of hydrous phases in the formation of trench parallel anisotropy: Evidence from Rayleigh waves in Cascadia, Geophys. Res. Lett., 40, 2642-2646, doi:10.1002/grl.50525.

Welch, M. D., and W. G. Marshall (2001), High-pressure behavior of clinochore, Am. Mineral., 86, 1380-1386.

Welch, M. D., A. K. Kleppe, and A. P. Jephcoat (2004), Novel high-pressure behavior in chlorite: A synchrotron XRD study of clinochore to 27 GPa, Am. Mineral., 89, 1337-1340.

Zanazzi, P. F., M. Montagnoli, S. Nazzareni, and P. Comodi (2007), Structural effects of pressure on monoclinic chlorite: A single-crystal study, Am. Mineral., 92, 656-661. 